\title{
Communication With Physicians as a Mediator in the Relationship Between the Nursing Work Environment and Select Nurse Outcomes in Jordan
}

\author{
Zaid Al-Hamdan, PhD, RN¹, Tanima Banerjee, $\mathrm{MS}^{2}$, \& Milisa Manojlovich, PhD, RN, CCRN³ (iD) \\ 1 Xi Alpha, Associate Professor, Jordan University of Science and Technology, Faculty of Nursing, Irbid, Jordan \\ 2 Statistician, University of Michigan, Institute of Healthcare Policy and Innovation Ann Arbor, MI, USA \\ 3 Rho, Professor, University of Michigan, School of Nursing, Ann Arbor, MI, USA
}

\begin{abstract}
Key words
Communication, international health/global health, professional issues, survey methodology, work environment/working conditions
\end{abstract}

\section{Correspondence \\ Dr. Milisa Manojlovich, University of Michigan, School of Nursing, 400 N. Ingalls, Room 4306, Ann Arbor, MI 48109.E-mail:mmanojlo@ umich.edu}

Accepted May 9, 2018

doi:10.1111/jnu.12417

\begin{abstract}
Purpose: To test whether communication mediated relationships among nurses' work environments and nurse outcomes of job satisfaction and intent to stay.

Design: This study used a cross-sectional, quantitative survey design to query 650 nurses who worked in three hospitals in Jordan.

Methods: We used Arabic versions of valid, reliable instruments measuring the nursing work environment, nurse perceptions of communication with physicians, intent to stay, and job satisfaction. Mediation analysis was used to test hypotheses.

Findings: A total of 582 questionnaires were returned (89.5\% response rate). Nurse perceptions of communication with physicians mediated the relationship between the nursing work environment and job satisfaction in medical, surgical, and critical care units. Nurse perceptions of communication with physicians mediated the relationship between the nursing work environment and intent to stay in all but maternity and "other" units.
\end{abstract}

Conclusions: Depending on the nurse outcome, communication was a significant mediator for various unit types. These results may be related to the type of work that is done in each unit and the influence of patient care. Communication is one of many mechanisms that can specify how a positive nursing work environment can contribute to nurses' job satisfaction and intent to stay.

Clinical Relevance: A potential solution to the nursing shortage in Jordan emerges by identifying communication with physicians as a mediator in the relationship between the work environment and selected nurse outcomes.
Poor communication between various healthcare team members, such as physicians and nurses, was recognized as a major cause of adverse events for hospitalized patients many years ago (Gawande, Zinner, Studdert, \& Brennan, 2003; Leape \& Berwick, 2005; Sutcliffe, Lewton, \& Rosenthal, 2004). This year, The Joint Commission added improving staff communication to its National Patient Safety Goals for 2018 (The Joint Commission, 2018), suggesting that the problem of poor communication continues. Although communication between all team members is important to patient outcomes, in this study we focused on communication between physicians and nurses because they represent the two healthcare disciplines that deliver the majority of care to hospitalized patients.

In several studies, high workloads (Aiken et al., 2011), nurse perceptions of poor nursing work environments (Liu et al., 2012), and disruptive or unprofessional behaviors by physicians (Rosenstein, 2017) were found to be driving forces that may foster and 
accelerate what is now a global nursing shortage problem (AbuAlRub, El-Jardali, Jamal, \& Abu Al-Rub, 2016). In fact, there are many driving forces that lead nurses to either change their work environments or entice them to stay in their current jobs. Research conducted in some countries has shown that to increase nurse job satisfaction and intent to stay, a work environment conducive to nursing practice and good communication with physicians is associated with job satisfaction and intent to stay (Gunnarsdóttir, Clarke, Rafferty, \& Nutbeam, 2009). However, the extent to which these same relationships among the work environment of hospital-based nurses, communication, and nurse outcomes such as job satisfaction and intent to stay exist in other countries remains an underexplored area. Thus, the purpose of this study was to test whether communication mediated relationships among nurses' work environments and nurse outcomes of job satisfaction and intent to stay. We tested the following hypotheses:

1. Communication will significantly mediate the relationship between nurses' work environments and job satisfaction; and

2. Communication will significantly mediate the relationship between nurses' work environments and intent to stay.

\section{Literature Review}

The work environment is one factor that plays a key role in nurses' job satisfaction, and by extension their intent to stay. But discovering how the work environment affects job satisfaction and intent to stay requires investigation of some other factor that would act as the mechanism, or the mediator, by which the work environment affects these two outcomes. Communication between nurses and physicians may be one factor that might explain how the work environment affects job satisfaction (Manojlovich, 2005). Wanzer and colleagues also showed a positive relationship between nurse-physician communication and nurses' job satisfaction, such that better communication was associated with greater job satisfaction (Wanzer, Wojtaszczyk, \& Kelly, 2009). In Cyprus, Lambrou and colleagues found that job satisfaction in one hospital was related to numerous factors, such as a positive working environment and effective communication among staff and supervisors (Lambrou, Kontodimopoulos, \& Niakas, 2010). Research investigating intent to stay has recently been associated with nurse managers' leadership styles (Al-Hamdan, Nussera, \& Masa'deh, 2016), although in a past study conducted in Jordan, relationships with physicians (which would depend on communication) were associated with nurses' intent to stay (Mrayyan, 2008). A common thread between these studies, even though they were conducted in different countries, is that a healthy work environment provides a fertile ground for effective communication, which then contributes to job satisfaction and intent to stay.

Jordan is a small kingdom in the Middle East. There are 31 public (government) hospitals, 12 military hospitals, and 2 teaching (university-affiliated) hospitals, with a total capacity of 8,071 beds. There are also 61 private hospitals with a total capacity of 3,989 beds. Registered nurses in Jordan spend approximately $48 \mathrm{hr}$ per week at work, where they are required to communicate effectively with physicians to optimize patient outcomes, but there is very little information about the relationship between nurse perceptions of their communication with physicians and job satisfaction in Jordanian hospitals. Moreover, although the nursing work environment has been a recent research focus in countries in the Middle East (AbuAlRub et al., 2016), we know little about the influence of the work environment on communication and nurse outcomes there.

\section{Methods}

\section{Study Design and Setting}

This study used a descriptive cross-sectional survey design. The setting for this study was three hospitals in Jordan: one public and one private hospital in Amman, and one teaching hospital in Irbid. Data were collected from June to October of 2014. Packets were distributed to all nurses working in one of the three hospitals during that time frame and included a cover letter explaining the aim of the study, demographic questions, and four study instruments.

\section{Participants}

All nurses who worked on inpatient units in one of the three hospitals were invited to participate. At the time of data collection, there were 1,000 registered nurses who worked in the three hospitals. There were 650 nurses who met the following inclusion criteria: (a) registered nurse, (b) at least 1 year of experience, and (c) working experience in a clinical unit. The 350 remaining nurses either did not meet inclusion criteria or were on annual leave. Information in the packets informed nurses that completing the questionnaires and returning them to the principal investigator 
implied providing informed consent. To maintain confidentiality and anonymity, participants were instructed to complete questionnaires anonymously (i.e., not to write their names on the questionnaires), to return the questionnaires in concealed envelopes, and to submit them directly to the first author (Z.A-H.). The study was approved by the Ethics Committees affiliated with the Jordan University of Science and Technology and all three hospitals.

\section{Data Collection}

A self-report questionnaire was used and consisted of four instruments and demographic questions. Questions were designed to understand Jordanian nurses' perceptions of their work environments, their communication with physicians, job satisfaction, and intent to stay. The administrative representatives of three study hospitals were contacted by the principal investigator (Z.A-H.) of this study to describe the data collection process. We conducted a power analysis (Cohen, 1992) to determine an adequate sample size since there were three hospital types (private, public, and teaching). To achieve $80 \%$ power, a medium population effect size, and twosided alpha of 0.05 , a minimum of 52 subjects from each hospital was needed, but we recruited more than the minimum number to account for nonrespondents and missing data.

\section{Measures}

Arabic versions of all four instruments used in this study were developed by experts in nursing. The content of these questions was translated and backtranslated by bilingual experts to meet international standards.

\section{Practice Environment Scale of the Nursing Work Index (PES-NWI)}

The nursing work environment was measured using the PES-NWI, which consists of five main concepts: (a) nurse participation in hospital affairs (nine items), (b) nurse foundations for quality care (10 items), (c) nurse managers' ability, leadership, and support of nurses (five items), (d) staffing and resource adequacy (four items), and (e) collegial nurse-physician relationships (three items). A Likert scale of 1 (strongly agree) to 4 (strongly disagree) was used for each of the items in this scale. In this study, the reliability coefficient (Cronbach's alpha) of this scale was 0.953, which is similar to what other researchers in international contexts have reported (Liu et al., 2012; Nantsupawat et al., 2011).

\section{Nurse-physician communication}

The overall Intensive Care Unit (ICU) Nurse-Physician Questionnaire (Shortell, Rousseau, Gillies, Devers, \& Simons, 1991) consists of 47 scales that measure multiple variables affecting relations between nurses and physicians. For this study, the four scales measuring between-group communication were used: openness (four items), accuracy (five items), timeliness (four items), and each other's understanding of the communication that occurs between nurses and physicians (eight items). The items are arranged on a 5-point Likert-type scale ranging from 1 to 5. An additional item measures overall communication satisfaction ("Overall, how satisfied are you with the communication between nurses and physicians in this unit?"; $1=$ very dissatisfied to $5=$ very satisfied). Although developed for use in ICU environments, the tool was used in a study of medical-surgical nurses (Doran, Sidani, Keatings, \& Doidge, 2002). Cronbach's alpha for the Arabic version, which was used in this study, was 0.92 .

\section{Job satisfaction}

The Global Job Satisfaction instrument (Pond \& Geyer, 1991) was used in this study. This instrument has a total of six items to assess respondents' general overview of job satisfaction on a 5-point Likert scale. Sample questions of this tool are: "All things considered, how satisfied are you with your current job?" ( 1 = not at all satisfied to $5=$ completely satisfied) and "How does this job compare to your ideal job?" $(1=$ very far from ideal and $5=$ very close to ideal). Cronbach's alpha for the Arabic version, which was used in this study, was 0.86 .

\section{Intent to stay}

The 6-item McCain's Intent to Stay scale evaluated nurses' intention to stay in their jobs on a 5-point Likert scale ranging from 1 (strongly disagree) to 5 (strongly agree). The Arabic version of McCain's Intent to Stay scale was used in the present study, and has been used previously with Jordanian nurses (AbuAlRub, Omari, \& Al-Zaru, 2009; Al-Hamdan, Nussera, et al., 2016). Sample items of this tool are: "I will not quit even if the job does not meet expectations" and "I plan to keep this job for at least 2-3 years." Cronbach's alpha for the Arabic version was 0.74 for the Intent to Stay scale.

\section{Data Analysis}

Descriptive statistics were calculated for demographic characteristics of the study participants, and for study 
variables. A complete case analysis approach was taken, since very few cases had missing data (i.e., two cases had missing values for job satisfaction). We generated histograms and scatter plots before conducting inferential statistics to determine if data distribution violated assumptions of normality. We also generated a correlation matrix using Pearson's $r$ as a screening tool to test for associations between all variables. Mediation analysis for Hypothesis 1 included these variables: nursing work environments, communication, and job satisfaction. The indirect effect of the nursing work environment on job satisfaction was determined by the product of (a) (the nursing work environment $\rightarrow$ communication path) and (b) (the communication $\rightarrow$ job satisfaction path). Mediation analysis for Hypothesis 2 included these variables: nursing work environments, communication, and intent to stay. The indirect effect of the nursing work environment on intent to stay was determined by the product of (a) (the nursing work environment $\rightarrow$ communication path) and (b) (the communication $\rightarrow$ intent to stay path). Following the recommendations by Zhao and colleagues (Zhao, Lynch, \& Chen, 2010), a bootstrap sampling technique using empirically derived sampling distribution (10,000 samples) of the indirect effects described by Preacher and Hayes (2004) was used to test both hypotheses. SAS 9.4 (SAS Institute Inc., Cary, NC, USA) was used for all analyses. Significance was determined at a twotailed $\alpha$ level of .05.

\section{Results}

A total of 582 questionnaires were returned (89.5\% response rate). Subjects were evenly distributed by gender, $58.7 \%$ belonged to the 25 - to 34 -year-old age group, and $66.7 \%$ were married. Most subjects were currently working as staff nurses $(71.4 \%)$ and had 6 years or more of job experience $(68.3 \%)$, and the majority of nurses in the sample had a bachelor of science in nursing degree $(81.4 \%)$. Nurses worked in a variety of units: medical, surgical, critical care, pediatric, maternity, and "other," which included staff development and administration units.

To test the first hypothesis, that communication will significantly mediate the relationship between the nursing work environment and nurses' job satisfaction, we used a bootstrap test to establish a mediation effect (Zhao et al., 2010). We also constructed 95\% confidence intervals (CIs) of the indirect effect (Preacher \& Hayes, 2004). At first, the mediating effects of communication were assessed separately for each unit type within the hospital in relation to the nursing work environment and job satisfaction. Higher values of the nursing work environment were associated with higher communication scores (i.e., nurses reported better communication with physicians) in critical care and "other" units; however, there was a significant inverse relationship between the nursing work environment and communication in medical, surgical, and pediatric units. Higher communication scores were associated with better job satisfaction among nurses (after controlling for the nursing work environment) in general, and this was true for all unit types except "other" units. Communication was a significant mediator for three unit types: medical, surgical, and critical care units out of a total of six unit types within the hospitals (Models 1 to 3, Table 1). In the remaining units

Table 1. Results From Mediation Analysis for the Outcome Job Satisfaction

\begin{tabular}{|c|c|c|c|}
\hline $\begin{array}{l}\text { Mediator model (unit } \\
\text { type) }\end{array}$ & $\begin{array}{l}\text { Estimate } \\
(S E)\end{array}$ & $\begin{array}{l}\text { Indirect } \\
\text { effect (SE) }\end{array}$ & $\begin{array}{l}95 \% \mathrm{Cl} \text { of } \\
\text { indirect effect }\end{array}$ \\
\hline \multicolumn{4}{|l|}{ Model 1 (medical units) } \\
\hline $\begin{array}{l}\text { Work environment } \rightarrow \\
\text { Communication }\end{array}$ & $-0.61(0.29)^{*}$ & \multirow[t]{3}{*}{$-0.17(0.08)^{*}$} & \multirow[t]{3}{*}{$(-0.33,-0.01)$} \\
\hline $\begin{array}{l}\text { Communication } \rightarrow \\
\quad \text { Job satisfaction }\end{array}$ & $0.28(0.04)^{*}$ & & \\
\hline Model 2 (surgical units) & & & \\
\hline $\begin{array}{l}\text { Work environment } \rightarrow \\
\text { Communication }\end{array}$ & $-0.83(0.32)^{*}$ & \multirow[t]{3}{*}{$-0.16(0.08)^{*}$} & \multirow[t]{2}{*}{$(-0.32,-0.01)$} \\
\hline $\begin{array}{l}\text { Communication } \rightarrow \\
\quad \text { Job satisfaction }\end{array}$ & $0.20(0.05)^{*}$ & & \\
\hline \multicolumn{3}{|l|}{ Model 3 (critical care units) } & \\
\hline $\begin{array}{l}\text { Work environment } \rightarrow \\
\text { Communication }\end{array}$ & $0.77(0.25)^{*}$ & \multirow[t]{2}{*}{$0.10(0.05)^{*}$} & \multirow[t]{2}{*}{$(0.02,0.21)$} \\
\hline $\begin{array}{c}\text { Communication } \rightarrow \\
\text { Job satisfaction }{ }^{a} \\
\text { Model } 4 \text { (pediatric units) }\end{array}$ & $0.14(0.04)^{*}$ & & \\
\hline $\begin{array}{l}\text { Work environment } \rightarrow \\
\text { Communication }\end{array}$ & $-0.98(0.40)^{*}$ & \multirow[t]{3}{*}{$-0.14(0.09)$} & \multirow[t]{3}{*}{$(-0.34,0.003)$} \\
\hline $\begin{array}{l}\text { Communication } \rightarrow \\
\quad \text { Job satisfaction }\end{array}$ & $0.15(0.06)^{*}$ & & \\
\hline Model 5 (maternity units) & & & \\
\hline $\begin{array}{l}\text { Work environment } \rightarrow \\
\text { Communication }\end{array}$ & $-0.30(0.73)$ & \multirow[t]{2}{*}{$-0.04(0.14)$} & \multirow[t]{2}{*}{$(-0.32,0.25)$} \\
\hline $\begin{array}{r}\text { Communication } \rightarrow \\
\text { Job satisfaction } \\
\text { Model } 6 \text { (other units) }\end{array}$ & $0.14(0.06)^{*}$ & & \\
\hline $\begin{array}{l}\text { Work environment } \rightarrow \\
\text { Communication }\end{array}$ & $1.43(0.57)^{*}$ & \multirow[t]{2}{*}{$\begin{array}{r}-0.002 \\
(0.14)\end{array}$} & \multirow[t]{2}{*}{$(-0.26,0.33)$} \\
\hline $\begin{array}{l}\text { Communication } \rightarrow \\
\quad \text { Job satisfaction }\end{array}$ & $-0.02(0.09)$ & & \\
\hline
\end{tabular}

Note. A 95\% confidence interval $(95 \% \mathrm{Cl}$ ) that does not include zero was considered as the criterion for significance of the mediation effect; if the confidence interval includes zero, an indirect effect of $a \times b$ is not significant.

a Job satisfaction means the effect of job satisfaction controlling for the nursing work environment.

*Significant $p$ values. 
(pediatric, maternity, and other), communication was not a significant mediator (Models 4 to 6, Table 1); thus, our first hypothesis was partially supported.

A similar analytic approach for mediation analyses described above was applied to examine our second hypothesis, that communication will significantly mediate the relationship between the nursing work environment and intent to stay. Higher communication scores were significantly associated with higher intent to stay scores, holding the nursing work environment constant for all unit types except "other." When units were examined separately, communication acted as a mediator for all but maternity and "other" units, providing partial support for our second hypothesis. The results from mediation analysis are portrayed in Table 2.

\section{Discussion}

The purpose of this study was to test whether communication mediated relationships among nurses' work environments and nurse outcomes of job satisfaction and intent to stay. We found partial support for the first hypothesis, because communication was a significant mediator in the relationship between the nursing work environment and job satisfaction only for nurses who worked in medical, surgical, and critical care units We also found partial support for the second hypothesis, because communication significantly mediated the relationship between the work environment and intent to stay for nurses who worked in all but maternity and "other" units. Thus, depending on the nurse outcome, communication was a significant mediator for various unit types.

These results may be related to the type of work that is done in each unit and the influence of patient care. The fact that in our study communication was not significant in "other" units, such as staff development units, may be a reflection of the type of work that is done in those units, which would affect nurse perceptions of communication with physicians. Nurses who work in pediatric or maternity units may derive more job satisfaction from either the patient population (e.g., children) or the nature of the work (e.g., assisting in the birthing process) than from communication with their physician colleagues. Similar to our findings, Delobelle and colleagues (2011), in a study conducted in South Africa, found that job satisfaction was significantly associated with the unit or ward in which nurses worked. No previous study in Jordan has investigated the effect of unit type on communication, the nursing work environment, and job satisfaction. However, one Jordanian study found significant differences between ward and intensive care unit nurses'
Table 2. Results From Mediation Analysis for the Outcome Intent to Stay

\begin{tabular}{|c|c|c|c|}
\hline $\begin{array}{l}\text { Mediator model (unit } \\
\text { type) }\end{array}$ & $\begin{array}{l}\text { Estimate } \\
\text { (SE) }\end{array}$ & $\begin{array}{l}\text { Indirect } \\
\text { effect } \\
(S E)\end{array}$ & $\begin{array}{l}95 \% \mathrm{Cl} \text { of } \\
\text { indirect effect }\end{array}$ \\
\hline \multicolumn{4}{|l|}{ Model 1 (medical units) } \\
\hline $\begin{array}{l}\text { Work environment } \rightarrow \\
\text { Communication }\end{array}$ & $-0.62(0.29)^{*}$ & $-0.76(0.36)^{*}$ & $(-1.49,-0.08)$ \\
\hline $\begin{array}{c}\text { Communication } \rightarrow \\
\text { Intent to stay }\end{array}$ & $1.26(0.18)^{*}$ & & \\
\hline \multicolumn{4}{|l|}{ Model 2 (surgical units) } \\
\hline $\begin{array}{l}\text { Work environment } \rightarrow \\
\text { Communication }\end{array}$ & $-0.82(0.32)^{*}$ & $-0.80(0.36)^{*}$ & $(-1.51,-0.07)$ \\
\hline $\begin{array}{c}\text { Communication } \rightarrow \\
\text { Intent to stay }\end{array}$ & $1.03(0.21)^{*}$ & & \\
\hline \multicolumn{4}{|l|}{ Model 3 (critical care units) } \\
\hline $\begin{array}{l}\text { Work environment } \rightarrow \\
\text { Communication }\end{array}$ & $0.77(0.25)^{*}$ & $0.45(0.26)^{*}$ & $(0.04,1.04)$ \\
\hline $\begin{array}{l}\text { Communication } \rightarrow \\
\text { Intent to stay }\end{array}$ & $0.59(0.21)^{*}$ & & \\
\hline \multicolumn{4}{|l|}{ Model 4 (pediatric units) } \\
\hline $\begin{array}{l}\text { Work environment } \rightarrow \\
\text { Communication }\end{array}$ & $-0.96(0.40)^{*}$ & $-0.70(0.38)^{*}$ & $(-1.55,-0.04)$ \\
\hline $\begin{array}{l}\text { Communication } \rightarrow \\
\text { Intent to stay }{ }^{a}\end{array}$ & $0.74(0.26)^{*}$ & & \\
\hline \multicolumn{4}{|l|}{ Model 5 (maternity units) } \\
\hline $\begin{array}{l}\text { Work environment } \rightarrow \\
\text { Communication }\end{array}$ & $-0.30(0.74)$ & $-0.32(0.81)$ & $(-2.16,1.13)$ \\
\hline $\begin{array}{c}\text { Communication } \rightarrow \\
\text { Intent to stay }\end{array}$ & $0.89(0.29)^{*}$ & & \\
\hline \multicolumn{4}{|l|}{ Model 6 (other units) } \\
\hline $\begin{array}{l}\text { Work environment } \rightarrow \\
\text { Communication }\end{array}$ & $1.62(0.54)^{*}$ & $0.92(0.75)$ & $(-0.28,2.64)$ \\
\hline $\begin{array}{c}\text { Communication } \rightarrow \\
\text { Intent to stay }\end{array}$ & $0.55(0.44)$ & & \\
\hline
\end{tabular}

Note. A 95\% confidence interval $(95 \% \mathrm{Cl})$ that does not include zero was considered as the criterion for significance of the mediation effect; if the confidence interval includes zero, an indirect effect of $a \times b$ is not significant.

antent to stay means the effect of intent to stay controlling for the nursing work environment.

*Significant $p$ values.

perceptions of their organization climates, which included support from physicians (Mrayyan, 2008).

Communication was also a significant mediator for the outcome of nurses' intent to stay for all but maternity and "other" unit types. Nurses who work in specialty units feel they are independent, and, as they have a special relationship with physicians, they believe they should be involved in any decision related to the patient (Al-Hamdan, Bawadi, Redman, \& AlNawafleh, 2016). Apker and colleagues suggested that nurses were less likely to leave a job if they felt that there was good communication between the team (Apker, Propp, \& Ford, 2009). Similar to our study, 
others have also found that the type of unit the nurses work in affects their intent to stay (Chan \& Morrison, 2000; Shader, Broome, Broome, West, \& Nash, 2001).

We found that the association between the work environment and communication was significant, but unexpectedly inverse for medical, surgical, and pediatric units in both models (i.e., outcomes of job satisfaction and intent to stay). Interestingly, the association between the work environment and communication was significantly positive in critical care units in both models, a finding consistent with a previous study conducted exclusively in critical care (Manojlovich \& DeCicco, 2007). One possible explanation for this finding is that there are other mediators affecting nurse perceptions of their work environment and communication that were not measured, consistent with our finding of partial mediation (Zhao et al., 2010).

Finally, it is interesting that job satisfaction and intent to stay did not vary together, also suggesting that unmeasured variables may influence relationships among work environment, communication, job satisfaction, and intent to stay. Other research, although not recent, has also shown differences when these two outcomes were studied jointly. In one study, nurse perception of management style was significantly related to nurse job satisfaction but not to intent to stay (Drews \& Fisher, 1996).

\section{Limitations}

We note several limitations to this study. The participants in this study were sampled from three hospitals in two cities in Jordan and did not cover all geographical areas in Jordan, so our findings cannot be generalized to the entire country. The study used self-report questionnaires, which introduces bias and limits our ability to determine actual relationships among concepts of interest. Participant responses may simply reflect their own self-image and their views of others, as individuals. However, self-report is the only method to determine job satisfaction and intent to stay. Small sample sizes in some unit types (maternity, other) may have contributed to nonsignificant mediation analysis results. Finally, as this was a cross-sectional study, it is not possible to make cause-and-effect statements.

\section{Conclusions}

Creating healthy work environments for nurses has gained international attention, and our study suggests that in Jordan, as in other countries, communication is a significant mediator in the relationship between the nursing work environment and nurse outcomes of job satisfaction and intent to stay. In effect, as a mediator, communication specifies how a positive nursing work environment can contribute to nurses' job satisfaction and intent to stay. Improving communication between nurses and physicians emerges as a potential strategy to contribute to greater job satisfaction and intent to stay. Both study hypotheses were partially accepted because of unexpected differences by unit type, adding an important nuance to the findings. Our results suggest that in future research other possible associations, such as supervisory management style, clinical practice variation by unit type, and patient population characteristics, be added to models to further clarify the picture of both what influences job satisfaction and intent to stay, and also how.

\section{Acknowledgment}

This study was supported financially by Jordan University of Science and Technology, Jordan.

\section{Clinical Resources}

Gi, T. S., Devi, M. K., \& Ang, E. N. K. A systematic review on the relationship between the nursing shortage and nurses' job satisfaction, stress and burnout levels in oncology/haematology settings. http://journals.lww.com/jbisrir/Abstract/201 1 /09390/A_systematic_review_on_the_relationship_ between.1.aspx

Virginia Henderson Global Nursing e-Repository. http://www.nursinglibrary.org/vhl/

\section{References}

AbuAlRub, R., El-Jardali, F., Jamal, D., \& Abu Al-Rub, N. (2016). Exploring the relationship between work environment, job satisfaction, and intent to stay of Jordanian nurses in underserved areas. Applied Nursing Research, 31, 19-23. https:// doi.org/10.1016/j.apnr.2015.11.014

AbuAlRub, R. F., Omari, F. H., \& Al-Zaru, I. M. (2009). Support, satisfaction and retention among Jordanian nurses in private and public hospitals. International Nursing Review, 56(3), 326-332. https:// doi.org/10.1111/j.1466-7657.2009.00718.x

Aiken, L. H., Cimiotti, J. P., Sloane, D. M., Smith, H., Flynn, L., \& Neff, D. (2011). Effects of nurse staffing and nurse education on patient deaths in 
hospitals with different nurse work environments. Medical Care, 49, 1047-1053. https://doi. org/10.1016/j.ijnurstu.2014.08.006

Al-Hamdan, Z., Nussera, H., \& Masa'deh, R. (2016). Conflict management style of Jordanian nurse managers and its relationship to staff nurses' intent to stay. Journal of Nursing Management, 24(2), E137-E145. https://doi.org/10.1111/jonm.12314

Al-Hamdan, Z. M., Bawadi, H. A., Redman, R. W., \& Al-Nawafleh, A. H. (2016). Perception of Jordanian nurses regarding involvement in decision-making. Applied Nursing Research, 30, el-e5. https://doi.org/ 10.1016/j.apnr.2015.06.013

Apker, J., Propp, K. M., \& Ford, W. S. Z. (2009). Investigating the effect of nurse-team communication on nurse turnover: Relationships among communication processes, identification, and intent to leave. Health Communication, 24(2), 106-1 14. https://doi.org/10.1080/10410230802676508

Chan, E., \& Morrison, P. (2000). Factors influencing the retention and turnover intentions of registered nurses in a Singapore hospital. Nursing $\theta$ Health Sciences, 2(2), 113-121. https://doi. org/10.1046/j.1442-2018.2000.00046.x

Cohen, J. (1992). A power primer. Psychological Bulletin, 112(1), 155-159. https://doi.org/10.1037/ 0033-2909.112.1.155

Delobelle, P., Rawlinson, J. L., Ntuli, S., Malatsi, I., Decock, R., \& Depoorter, A. M. (2011). Job satisfaction and turnover intent of primary healthcare nurses in rural South Africa: A questionnaire survey. Journal of Advanced Nursing, 67(2), 371-383. https://doi. org/10.1111/j.1365-2648.2010.05496.x

Doran, D. I., Sidani, S., Keatings, M., \& Doidge, D. (2002). An empirical test of the Nursing Role Effectiveness Model. Journal of Advanced Nursing, $38(1), 29-39$.

Drews, T. T., \& Fisher, M. L. (1996). Job satisfaction and intent to stay: RNs' perceptions. Nursing Management, 27(3), 58.

Gawande, A. A., Zinner, M. J., Studdert, D. M., \& Brennan, T. A. (2003). Analysis of errors reported by surgeons at three teaching hospitals. Surgery, 133(6), 614-621. https://doi.org/10.1067/ msy.2003.169

Gunnarsdóttir, S., Clarke, S. P., Rafferty, A. M., \& Nutbeam, D. (2009). Front-line management, staffing and nurse-doctor relationships as predictors of nurse and patient outcomes. A survey of Icelandic hospital nurses. International Journal of Nursing Studies, 46(7), 920-927. https://doi. org/10.1016/j.ijnurstu.2006.11.007
The Joint Commission. (2018). 2018 national patient safety goals. Retrieved from https://www. jointcommission.org/hap_2017_npsgs/

Lambrou, P., Kontodimopoulos, N., \& Niakas, D. (2010). Motivation and job satisfaction among medical and nursing staff in a Cyprus public general hospital. Human Resources for Health, 8(1), 26. https://doi.org/10.1186/1478-4491-8-26

Leape, L. L., \& Berwick, D. M. (2005). Five years after To Err is Human: What have we learned? Journal of the American Medical Association, 293(19), 2384-2390. https://doi.org/10.1001/jama.293.19.2384

Liu, K., You, L. M., Chen, S. X., Hao, Y. T., Zhu, X. W., Zhang, L. F., \& Aiken, L. H. (2012). The relationship between hospital work environment and nurse outcomes in Guangdong, China: A nurse questionnaire survey. Journal of Clinical Nursing, 21(9-10), 1476-1485. https://doi. org/10.1111/j.1365-2702.2011.03991.x

Manojlovich, M. (2005). Linking the practice environment to nurses' job satisfaction through nurse-physician communication. Journal of Nursing Scholarship, 37(4), 367-373. https://doi.org/10.1111/ j.1547-5069.2005.00063.x

Manojlovich, M., \& DeCicco, B. (2007). Healthy work environments, nurse-physician communication, and patients' outcomes. American Journal of Critical Care, $16(6), 536-543$.

Mrayyan, M. T. (2008). Hospital organizational climates and nurses' intent to stay: Differences between units and wards. Contemporary Nurse, 27(2), 223-236. https://doi.org/10.5172/conu.2008.27.2.223

Nantsupawat, A., Srisuphan, W., Kunaviktikul, W., Wichaikhum, O. A., Aungsuroch, Y., \& Aiken, L. H. (2011). Impact of nurse work environment and staffing on hospital nurse and quality of care in Thailand. Journal of Nursing Scholarship, 43(4), 426-432. https://doi.org/10.1111/ j.1547-5069.2011.01419.x

Pond, S. B., \& Geyer, P. D. (1991). Differences in the relation between job satisfaction and perceived work alternatives among older and younger blue-collar workers. Journal of Vocational Behavior, 39(2), 251-262. https://doi.org/10.1016/ 0001-8791(91)90012-B

Preacher, K. J., \& Hayes, A. F. (2004). SPSS and SAS procedures for estimating indirect effects in simple mediation models. Behavior Research Methods, Instruments, $\theta$ Computers, 36(4), 717-731. https://doi.org/10.3758/BF03206553

Rosenstein, A. H. (2017). Disruptive and unprofessional behaviors. In K. J. Brower \& M. B. Riba (Eds.), Physician mental health and well-being 
(pp. 61-85). Basel, Switzerland: Springer International. https://doi.org/10.1007/

978-3-319-55583-6

Shader, K., Broome, M. E., Broome, C. D., West, M. E., \& Nash, M. (2001). Factors influencing satisfaction and anticipated turnover for nurses in an academic medical center. Journal of Nursing Administration, 31(4), 210-216. https://doi.org/10.1097/00005110-20010400000010

Shortell, S. M., Rousseau, D. M., Gillies, R. R., Devers, K. J., \& Simons, T. L. (1991). Organizational assessment in intensive care units (ICUs): Construct development, reliability, of the ICU Nurse-Physician Questionnaire. Medical Care, 29(8), 709-726.
Sutcliffe, K. M., Lewton, E., \& Rosenthal, M. M. (2004). Communication failures: An insidious contributor to medical mishaps. Academic Medicine, 79(2), 186-194. Retrieved from http://www.ncbi. nlm.nih.gov/pubmed/14744724

Wanzer, M. B., Wojtaszczyk, A. M., \& Kelly, J. (2009). Nurses' perceptions of physicians' communication: The relationship among communication practices, satisfaction, and collaboration. Health Communication, 24, 683-691.

Zhao, X., Lynch, J. G., \& Chen, Q. (2010). Reconsidering Baron and Kenny: Myths and truths about mediation analysis. Journal of Consumer Research, 37(2), 197-206. https://doi. org/10.1086/651257 